\title{
Enhancing Curriculum in Epidemiology and Biostatistics through Simulation-Based Learning
}

\author{
Sharn Donnison (Corresponding author) \\ School of Education, University of the Sunshine Coast \\ Locked Bag 4, Maroochydore DC Queensland 4558 Australia \\ Tel: 07-5459-4671Ｅ-mail: sdonniso@usc.edu.au
}

\section{Peter Dunn}

School of Health and Sport Sciences, University of the Sunshine Coast Locked Bag 4, Maroochydore DC Queensland 4558 Australia Tel: 07-5456-5085Ｅ-mail: pdunn2@usc.edu.au

\section{Rachel Cole}

School of Health and Sport Sciences, University of the Sunshine Coast Locked Bag 4, Maroochydore DC Queensland 4558 Australia

Tel: 07-5459-4656_E-mail: rcole@usc.edu.au

\section{Michael Bulmer}

School of Mathematics and Physics, University of Queensland Queensland 4072 Australia

Tel: 07-3365-7905 E-mail:m.bulmer@uq.edu.au

\section{Anne Roiko}

School of Medicine, Griffith University

Gold Coast campus, Queensland 4222 Australia

Tel: 07-5552-7870Ｅ-mail: a.roiko@griffith.edu.au 
Frank Muller

School of Health and Sport Sciences, University of the Sunshine Coast

Locked Bag 4, Maroochydore DC Queensland 4558 Australia

Tel: 07-5430-1234Ｅ-mail: fmuller@usc.edu.au

\author{
Received: July 28, 2015 Accepted: September 29, 2015 Published: November 12, 2015 \\ doi:10.5296/ire.v4i1.8064ＵRL: http://dx.doi.org/10.5296/ire.v4i1.8064
}

\begin{abstract}
A course in epidemiology and biostatistics, taken by students in health promotion and other public health disciplines, is evaluated and assessed in light of a recent university directive to incorporate blended learning, and the projected increase of online students into the course. A formal curriculum evaluation was informed by qualitative data from academic staff teaching into the course and students enrolled in the course. Five areas of challenge are identified: the volume of content; the authenticity of content; the course scheduling; the disconnection between the two course components; and the authenticity of the assessment. Some potential solutions have been identified, and the use of a virtual human population proposed as an avenue for introducing these solutions in a blended learning context. The process of conducting a formal curriculum evaluation in the context of introducing blended learning may prove useful in higher education courses looking to introduce blended learning, especially in disciplines that require students to interact with people.
\end{abstract}

Keywords: virtual population, curriculum evaluation

\title{
1. Introduction and Background
}

Teaching in higher education is always in a state of change, adapting to new government and university policies (and the budget ramifications), technological developments, changing student demographics, and innovations in pedagogical theory and practices. Recently, changes to how teaching and learning is theorized and enacted in the classroom as a result of technological advances has led to the incorporation of blended learning into higher education courses. Blended learning is generally considered to include elements of both face-to-face teaching and computer-aided teaching methods in a pedagogically-sound manner (Alammary et al., 2014). This paper describes how an existing epidemiology and biostatistics course studied by public health students in an Australian university was redesigned in light of the University adopting a blended learning approach to teaching.

Blended learning can be implemented in at least three different forms (Alammary et al., 2014): a low impact blend, where extra activities are added to an existing course; a medium-impact blend, where some face-to-face activities are replaced by computer-aided 
components; or a high-impact blend where a course is redesigned from scratch. In the current context, the teaching staff decided to adopt the high-impact blend and redesign the course. This necessitated an evaluation of the existing curriculum particularly with an emphasis on how the course could be redesigned to include computer-aided learning components.

Building a new blended learning course from scratch comes with benefits and challenges. Benefits of the high-impact approach include an opportunity to reduce problems that exist in the current course and to make enhancements at the same time, which can lead to a more successful course (Graham, 2012). This approach also can lead to better integration compared to the other methods (Littlejohn \& Pegler, 2007) and allows teachers to extract the maximum benefit of blended learning for their students as they consider a wider array of technologies to integrate into the course (Carman, 2002). Challenges include the large amount of resources, time and experience necessary for such a large undertaking.

This paper first discusses the context for the redevelopment of the course and describes the 2013 offering of the course, the findings of a course evaluation, then some strategies adopted by the course teaching team for redesigning the course, with particular attention to incorporating technology into the course via a simulated population using The Island. The process reveals general principles that could apply in the redevelopment of other higher education courses.

\section{The Context}

The focus of this paper is the course PUB361 Epidemiology and Biostatistics, offered at the University of the Sunshine Coast (USC), a small Australian regional university (8904 enrolments in 2013). The course had been offered at USC for over 10 years and had evolved, incrementally, over that time. The course was a required third-year course in public health undergraduate programs in health promotion, environmental health science, nutrition, and nutrition and dietetics. The course was also studied by post-graduate students in the Masters of Health Promotion program (on-campus and online). The total enrolment was over 70 students in 2013. PUB361 had six teaching weeks of course work dedicated to epidemiology, six weeks dedicated to biostatistics and one teaching week in which the two strands overlapped. Course delivery included one two-hour lecture and one two-hour tutorial per week for thirteen teaching weeks. Tutorial classes were held in computer laboratories (so students could use software such as SPSS and OpenEpi).

Undergraduate students in PUB361 had studied a recommended pre-requisite introductory statistics and research methods course in their first year of study, but many students studying the Master of Health Promotion had not. While ostensibly a third-year undergraduate course, the epidemiology content and a large part of the biostatistical content in PUB361 was introductory. Course content included approaches to, methodologies and uses for both epidemiology and biostatistics. The epidemiological strand covered fundamental epidemiological concepts and epidemiological study designs, and how to evaluate epidemiological research findings. The biostatistics component built on basic statistical concepts and methods of collecting and analysing quantitative epidemiological data. More specifically, the learning outcomes proposed that students should be able to: 
1) Formulate hypotheses that can be addressed through epidemiological investigations;

2) Identify and apply techniques to reduce bias and control for confounding at the design and analysis phases of an epidemiological study;

3) Collect and evaluate information about epidemiological research designs and statistical analysis, to draw conclusions about public health significance;

4) Plan and conduct a biostatistical analysis and produce a report; and

5) Identify and describe characteristics of, define terminology associated with, and calculate measures relevant to the epidemiological approach.

Students demonstrated their achievement of the learning outcomes through (i) designing and reporting on epidemiological research designs and studies; (ii) analysing and interpreting quantitative datasets and producing statistical reports for biostatistics; and (iii) interpreting tables, results and conclusions in research articles in an open book exam.

Many converging factors led to a redesign of the course. Traditionally, the course had been offered as an on-campus, undergraduate course with one or two online, postgraduate enrolments. However, the number of online-only postgraduate students (mainly international students) was expected to increase substantially in the following years. Secondly, the University has recently instituted an emphasis on embedding e-Learning into course and program design (University of the Sunshine Coast, 2012). Thirdly, recent changes to the teaching staff meant that some level of change was inevitable in any case: the experienced epidemiology lecturer had left the University, and the teaching of the epidemiological strand was to be delivered by a lecturer with little experience in academia, but with recent industry experience. The opportunity to reconsider the design and delivery of this course was timely.

\section{3. e-Learning in Higher Education}

Since the late 1990s there has been an increasing call to incorporate e-Learning into Higher Education curricula, learning and teaching to improve student learning outcomes and to enrich the student experience (Lee \& McLoughlin, 2010; Thomas, 2011).

e-Learning and, particularly, Virtual Learning Environments (VLE) have proven benefits when employed within the context of sound models of instruction such as problem-based learning (Kim \& Reeves, 2007). Authentic task simulations, such as VLE, are becoming widely adopted in university online and blended courses in disciplines as diverse as education and political science (Reeves \& Reeves, 2012). VLE have many potential pedagogical benefits such as providing access to learning opportunities to widely dispersed learners with flexible education needs, a growing concern for many universities everywhere (Reeves \& Reeves, 2012). They also allow authentic tasks to be incorporated into learning activities that are inherently motivating (Reeves \& Reeves, 2012) and are more engaging that traditional static and teacher-led lectures (Arum \& Roksa, 2011; Kuh, 2003). VLE also provides opportunities for group simulation tasks that can foster better collaboration among learners by nurturing a sense of community (Roberts, 2004). Research summarised by Herrington et al. 
(2010) demonstrated that online discussions within the context of completing authentic tasks are both natural and productive; learners engage in rich, meaningful discussions to accomplish their collaborative work.

\section{Virtual Learning Environments in the Context of Epidemiology and Biostatistics}

Epidemiology is the study of "the distribution and size of disease problems in human populations" (Everitt, 2006, p.141), hence Virtual Learning Environments are particularly beneficial to the study of epidemiology, where engaging students in real-life epidemiological research design and data collection can be difficult (Linden et al., 2011; Bulmer \& Haladyn, 2011). Furthermore, the learning outcomes sought in the course are consistent with the learning mechanism explained using virtual worlds (Loke, 2015) such as decision making and vicarious experiences.

Epidemiological studies often require primary data to be collected while others rely heavily on secondary data. Traditional epidemiology courses focus on the analysis of secondary data for both reasons of authenticity (analysis of secondary data is a common part of what a real epidemiologist does) and practical reasons (collecting primary data requires ethics approval, can take substantial time, and often requires access to populations with the appropriate (and often rare) diseases). Consequently, introductory epidemiology courses usually focus on secondary data, and using existing data, published research articles, theoretical and practical discussion, and role playing. Providing experience with primary data is more difficult, and if such experiences are included in the course students may resort to collecting data from their friends and family as 'subjects', raising ethical concerns; or, using equipment and resources outside the scope of the course. This form of primary data collection may actually reinforce a trivial view of the role of data analysis (Bulmer \& Haladyn, 2011). Alternatively, courses may avoid primary data collection altogether. One pedagogical advantage of primary data collection is that is enables students to experience first-hand the subtleties and practicalities of collecting data, which are invaluable even in the study of secondary data sets.

One way for students to gain experience with primary data is for students to collect their own data in a virtual environment (Wild, 2007). Many "virtual worlds" are being developed to provide students with a holistic appreciation of their studies (Bulmer, 2011). Such environments are particularly useful in helping students understand issues in epidemiological research design by giving them non-trivial settings, such as simulations of virtual vaccination trials (Duchateau et al., 2010); give students a context to the research and data they are using; and providing a platform for project work and a motivation for learning research and statistical reasoning (Forster \& MacGillivray, 2010).

Advantages of this pedagogy are that students can design an epidemiological study, then collect data from a population of people, without requiring ethical approval, without raising health and safety concerns, without taking too much time, and by using diseases known to be present in the virtual population (Linden et al., 2011). PUB361 had never included substantial amounts of e-Learning, and specifically no virtual learning components or primary data collection, and the push for blended learning offered the context in which to trial this adoption. 


\section{Methodology}

In anticipation of a course redesign, a formal curriculum evaluation of the 2013 offering of PUB361 was conducted using Print's (1993) six-step approach: (1) describe the nature of the evaluation; (2) identify the specifications of the evaluation; (3) plan the design of the evaluation; (4) collect data; (5) analyse data; and (6) prepare conclusions.

The nature of the evaluation (Step 1) was constrained by internal and external accreditation requirements, staff expertise and workloads, government legislation, and University policies. Changes were made within this context.

The specifications of the evaluation (Step 2) refer to the purpose and audience for the evaluation. The main purpose was to redesign the course to improve the student experience and learning outcomes within the context of an institutional requirement of blended learning approach. The direct audience is the teaching team, though future students will be the main beneficiaries.

The design of the evaluation (Step 3) included collecting data from the students enrolled in the course and the four teaching staff involved in the 2013 course offering. All the teaching staff involved in 2013 had taught the course at least once before so their experience was not limited to just one offering.

The data collection included qualitative information from the end-of-semester, anonymous, online Student Evaluation of Teaching and Course (SETAC) evaluations (completed by 20 of 63 students (33.9\% response rate)), one 30-minute focus group with two anonymous student volunteers, and a one-hour focus group comprising the lecturer and the tutor in epidemiology and the lecturer and tutor in biostatistics.

The focus groups were facilitated by a research assistant not connected with PUB361, then professionally transcribed. The recorded data from the focus group interviews were analysed using a modified version of Glaser and Strauss's (1967) grounded theory where themes and sub-themes were identified. These included content (the volume and the authenticity); the authenticity of the assessment; the course structure; and the disconnection between the epidemiology and biostatistics components. We now discuss the results and analysis of this data (Step 5), and the conclusions drawn from them (Step 6).

\section{Results}

\subsection{Content: The volume}

Data from both focus groups and SETAC evaluations strongly indicated that the volume of content was a common concern for staff and students, with the biostatistics component being the major concern:

students $[\ldots]$ were desperately still trying to learn things only a matter of days before assignments were due [...] there was no reflection. People like me anyway need several weeks to think and digest and make sense of material but these students have no time, it 
was just a rush to finish the last topic and then try to incorporate that in part of their assessment. (Staff focus group)

Teaching staff and students agreed that the course had a high workload causing considerable difficulty for the students:

There's a lot of content to cover within 13 weeks [...] there's just too much content. (Staff focus group)

There is way too [much] information being crammed into this course in the semester. (Student SETAC comment)

To explain, the statistical techniques taught in the biostatistics component of the course alone were: sample size estimation; graphical summaries (e.g. barcharts; histograms; boxplots; scatterplots); numerical summaries (e.g. means; medians; standard deviations, etc.); $t$-tests and confidence intervals (for one mean, paired means, two independent sample means); one-way analysis of variance; non parametric tests (e.g. Mann-Whitney; Kruskall-Wallis); simple linear regression; multiple linear regression (including using dummy variables and interactions); relative risks and odds ratios (including confidence intervals); chi-squared tests; and simple and multiple logistic regression. The use of SPSS (statistical software) for most of the above techniques was also taught.

To place the above in context for the PUB361 students: (i) most students had never used SPSS, and many had never used any statistical package; (ii) undergraduate students had usually studied the pre-requisite material two years previously, while many postgraduate students had never seen that material at all; (iii) many students were not, in general, quantitatively-minded and many were enrolled in non-quantitative disciplines; and (iv) the biostatistical strand was taught and assessed in six weeks. Altogether, the biostatistical strand had a high cognitive demand mainly due to the amount of content being covered in a short time period, especially for students who have never studied statistics before.

One reason for the volume of content is that staff have had to teach the statistical software, as well as application of the software for almost all of the statistical techniques:

...you can learn the statistics but then you've also got to learn how to make it happen in practice by learning the software as well, so they're two different learning experiences but happening [in] parallel. (Staff focus group)

Furthermore, learning to use the statistical software was necessary so students could complete their reports as part of course assessment; however, teaching students to use the software was complicated and time-consuming:

...you can teach [the students] the statistics, but then teaching them how to do that in [SPSS] is an entire course in itself because it is not straightforward, it is not clear, there's so many intricacies and idiosyncrasies with [SPSS]... (Staff focus group)

To achieve the learning outcomes of the course, the students needed to use the software, but proficiency in the software was not itself an explicit learning outcome. Some staff members 
suggested using a simpler statistical software package; however, the use of SPSS is driven by institutional factors as SPSS is the only statistical software licenced and supported by the university.

The lack of pre-requisite skills of a small proportion of students is partially responsible for the high cognitive load:

Having never done stats before, [I] found the course very challenging and frustrating (Student SETAC comment)

I haven't done any statistics courses prior and I found it really difficult just picking up basic concepts of stats (Student focus group)

There are some who haven't done statistics before, extra help need [sic] to be given. (Student SETAC comment)

[...] some students have a background where they have seen some statistics before but there are some students who've never seen it before... (Staff focus group)

\subsection{Content: The Authenticity}

Staff were best placed to determine authentic content for PUB361, as two of the staff members had recent industry experience in epidemiology and biostatistics. Thus, the focus turns to the relevance of this course for future study, research and employment:

... when they pick up a journal paper I want them to be able to understand and make some sense of what it means and to be able to [...] evaluate what they read, so they pick it up, they can see a confidence interval they know what it means, they can see a $P$-value, they know what that means, they can look at a research study and try to make some sense of whether it was well done. (Staff focus group)

[The students] are going to be out as a practitioner in the real world so they'll have to keep up-to-date with the latest evidence and that sort of thing, so they need to be able to go to literature, the research and make sense of it and critique an article. A lot of them may have to also deal with data and collecting some data, so having some of the basic concepts around epi data, what are good sources of data, where do you go for that... (Staff focus group)

While staff members agreed that the learning objectives of the course were authentic, they had reservations about the details of the content:

[...] you don't have to teach all the intricacies of everything, just enough to make some sense of it and enough to then make them realise if you actually want to do some of this yourself, you go and ask someone who is in the know because you don't know enough yet. (Staff focus group)

We need to seriously look at the concepts that we're teaching and really scale back, but we need to do it better in terms of delivery. (Staff focus group) 
This implies that the detailed content should be reviewed in any redesign of the course, to ensure that students achieve the learning outcomes of the course, retain the knowledge necessary for the workplace, yet are not overburdened by too much detail.

\subsection{The scheduling of the course}

A common response to the volume of content is suggesting that the course be split into two courses, either one for epidemiology and another for biostatistics, or two combined courses:

Again I think the major thing is that there's just too much for one semester. (Staff focus group)

...break up Epidemiology and Biostatistics into two different classesi, as I feel and think they are two big areas (Student SETAC comment)

there just isn't enough time to cover the content we need to cover [...] my wish would be not to split the course into two separate but two united together (Staff focus group)

Staff made suggestions about where to locate this extra course in the undergraduate programs, because those students in PUB361 who had covered the recommended pre-requisite statistics course usually had done so two years earlier, so that most of the material had been forgotten and, regrettable, unused:

...it would be great to have a first-year and a second-year and a third-year course so you can keep building, and you can gradually get to a point where you'd like them to get to, and the ideas keep getting built upon rather than something in your very first semester at university, everyone forgets and then all of a sudden you've got three course all in one. (Staff focus group)

[...] by the time you get to mid third-year they've forgotten it [the pre-requisite material] even if they had done stuff. (Staff focus group)

Despite this sensible suggestion, the ability to split PUB361 into two courses, effectively adding a new course, is limited in practice in the undergraduate programs because, as one staff member noted, "the [undergraduate] programs that use this course simply don't have that capacity to take it on" due to external and internal accreditation requirements.

However, recent changes to the rules regulating academic standards in Australia (AQF, 2015) created the opportunity to add an additional, required statistics course to the Master of Health Promotion. Rather than adding a new course created by splitting PUB36, this new course would be a Masters-level introductory statistics course, ensuring postgraduate students entering PUB361 would have at least an equivalent level of statistics as the undergraduate students.

\subsection{The authenticity of the Assessment}

Authentic assessment is best guided by what is needed in practice, so that teaching staff are better placed to comment that students, especially because the teaching staff in PUB361 
collectively had a mix of academic expertise, industry expertise, contacts in industry, and were actively researching in the area.

Parts of the assessment were authentic: comparing epidemiological designs and interpreting tables in articles, for example, are authentic tasks. However, teaching staff agreed that some of the assessment required students to perform tasks that they would not be qualified to do in any workplace (such thoroughly analyse an existing, raw, messy, large dataset and produce a comprehensive report on this analysis). Staff members agreed that no students graduating from their program with PUB361 as their only (or second) statistics subject should be expected to complete such a task in the workplace without expert support and input. Instead, they should have a grasp of the essential concepts and language, to empower them to communicate effectively with relevant experts in the field and be able to critique appropriate literature. In other words, the assessment needed to be aligned with the course objectives, taking into account the students now entering PUB361 and their background.

\subsection{The disconnection between the two components}

In practice, the epidemiological component of a research project establishes the study design, from which data are collected that are then analysed using biostatistics. While PUB361 contains strands in epidemiology and biostatistics, for many years the two strands were taught with separate teaching staff and hence did not appear to students to be connected (even though teaching staff did make some connections between the strands). In addition, the assessment tasks for each strand were not connected, even though these two components are tightly connected in practice. Students also identified some difference in terminology between the two components of the course:

[...] I found it difficult because I hadn't heard the words [...] "response variable". We had used with [the epidemiology component] "outcome" [... ]: different terminology. (Student focus group)

This terminology issue can be overcome by ensuring the teaching staff in both strands are communicating and sharing resources, or even teach across the strands.

In addition, the biostatistics assessment was based around a large secondary dataset with no connection to the epidemiological strand:

The one [factor] we don't do well is plan and conduct a study[...] plan and conduct a biostatistical analysis. We almost just do the planning but never analyse it, and then sometime later we don't do the planning but we do do the analysis (Teaching staff focus group).

The analysis of secondary data is not inauthentic, as noted earlier, but without an experience of designing and collecting their own data, the students could not appreciate the subtleties and practicalities of collecting data, the value of the data (Bulmer \& Haladyn, 2011) and also had little understanding and no ownership of the data (Rumsey, 2002).

To further emphasise this division, teaching staff (lecturer and tutor) changed when the biostatistical component of the course began. Students identified this disconnection also: 
The sudden leap to bio statistics [sic] was challenging. (Student SETAC comment)

\subsection{Summary}

Five key areas have been identified as areas for improvement or consideration. These can be divided into two areas (Figure 1): Those emerging from external factors (the influx of online students; the need to incorporate blended learning), and those areas emerging from the course evaluation (the volume of content; the disconnection between epidemiology and biostatistics; the authenticity of the content; the authenticity of the assessment; the course scheduling). Some future directions are now identified.

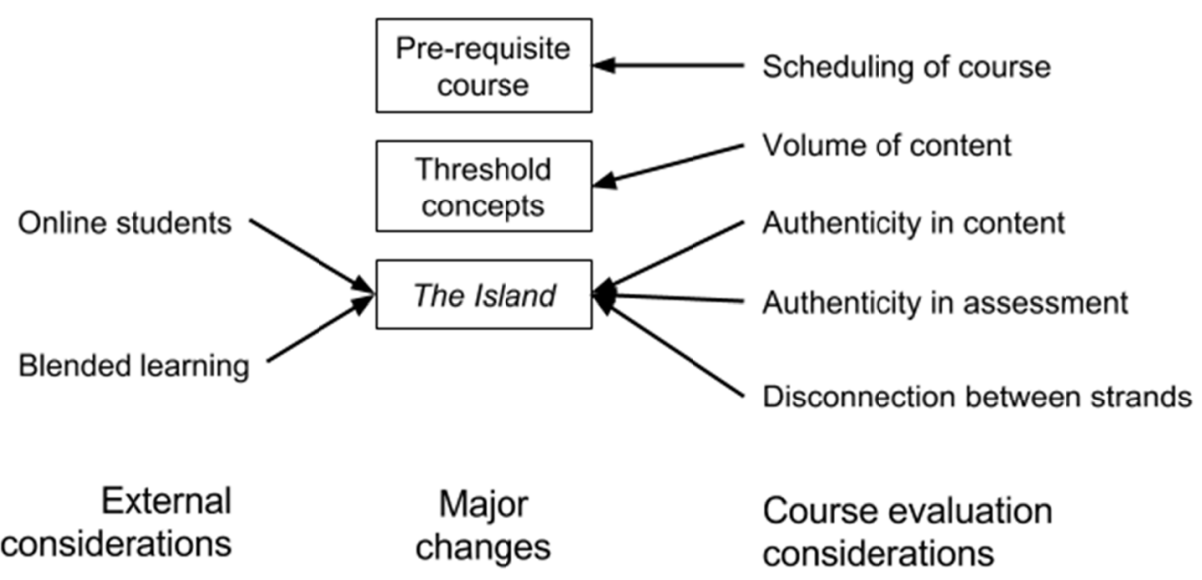

Figure 1. Identified problems with PUB361 and potential solutions

\section{Future Directions}

Considering the above evaluation, suggestions can be made into each of the five identified areas. The focus in the paper is how to incorporate these suggestions while introducing a blended learning component to the course in the form of a VLE. This will require staff teaching into PUB361 to reconsider how the course is conceptualised, delivered and assessed. A VLE appropriate to this course is The Island (Bulmer \& Haladyn, 2011), which was originally developed to support learning in epidemiology (Bulmer, 2010).

The Island is a virtual fictitious island populated by Villagers:

The backstory for this Island is that it was settled by survivors of a shipwreck in 1779 and has since grown to a population of around eight thousand Islanders spread across 38 villages [...] (Bulmer 2010, p. 23)

To use The Island, students devise a research question, develop an epidemiological study design, collect data from selected villagers who complete specific tasks (such as drinking an alcoholic drink, and their blood pressure measured) and then analyse the findings using a statistical software package. 
A typically interaction with Villagers may proceed as follows: Students select a sample of Villagers, and collate something of interest from these villagers (such as blood pressure). In some cases, Villagers can be asked to perform a task (such as drinking an alcoholic drink), and the outcome re-measured. The simulation of the population evolves in real time (based on mathematical modelling), so that (for example) the blood pressure response to drinking alcohol in the above example will take time (the effects will not be instantaneous), as in real life, and blood pressure readings will be related to many other variables as well. The data collection process also incurs a time cost upon students, to reinforce the value of data (Bulmer \& Haladyn, 2011).

Using The Island in PUB361 provides an 'authentic' instructional focus around which the content, teaching, learning and assessment can be redeveloped and aligned. Secondly, it provides an engaging and motivating teaching and learning tool for students to achieve the existing course learning outcomes. Thirdly, it also acts as a signature pedagogy (Gurung, Chick \& Haynie, 2009) in that it will potentially shape the pedagogies and practices in the course while also inducting the students into the discourses that are fundamental to the disciplines of biostatistics and epidemiology. Fourthly, the design of The Island intentionally incorporates some of the practical issues of real-world studies. Finally, using The Island links epidemiology and biostatistics as it enable students to design a study and collect the data and to analyse that same data.

Establishing The Island as the instructional focus for the course means course content, assessment and pedagogies need to be re-examined. In doing so, many of the issues raised by the staff and students in the course evaluation will be partially addressedl. A priority for the course is to redesign the course assessment and to consider how The Island can be used to achieve the learning outcomes addressed by the assessment tasks, but other means of addressing the evaluation findings are also noted.

\subsection{Scheduling of Course}

The location of the course in undergraduate programs of study is determined by factors outside the control of the teaching team: the programs do not have space within their structures to accommodate an additional course. However, some undergraduate programs have decided (independently of this curriculum evaluation) to move the pre-requisite introductory statistics course into second year, and hence reduce the time between that introductory course and PUB361. This means that, for the foreseeable future, the course remains in the third year of each undergraduate degree program.

The postgraduate students in the Master of Health Promotion, who may or may not have completed any pre-requisite studied in statistics, will now be required to complete a new course in introductory statistics as mentioned above. This means that all students entering PUB361 can be expected to have similar pre-requisite statistical studies, but some undergraduate students may have covered this two years previous.

\subsection{Volume of content}


The introduction of a new introductory statistics course in the Masters program means that all students will have studied the required pre-requisite content, even if some time previous, so that the initial biostatistical content can be completed in slightly less time.

Teaching staff also considered the learning outcomes and determined what skills and knowledge, and at what level, are actually required to achieve the learning outcomes:

So maybe understanding some of those basic concepts in a more simplified way-in a more realistic way, which they'll probably do in the real world-might be more appropriate. (Staff focus group)

The volume of content can be moderated by focussing and building on threshold concepts (Meyer \& Land, 2005, p. 373). Furthermore, the teaching of SPSS can be restricted to those methods necessary for completion of the assessment, and the more advanced techniques (such as logistic regression) can be taught without implementation in SPSS (and instead, taught for interpreting journal articles that use logistic regression).

\subsection{Authenticity of content}

The content of the existing course contains many authentic elements, including the use of secondary data. However, the introduction of The Island allows the authenticity to extend to the collection of primary data also. This contributes to the authenticity associated with the study of secondary data also, since participating in the design and collection of data helps students to appreciate the subtleties, practicalities, and the value of all data.

The focus, content and tasks of The Island directly relate to most of the students' public health programs of study such as health promotion (what happens when people are asked to follow certain healthy or unhealthy behaviours), and nutrition and dietetics (what happens after eating or drinking certain foods). Further iterations of The Island will include more tasks related to Environmental Health Science.

\subsection{Authenticity of assessment}

The assessment in the existing course is authentic in many ways. Introducing The Island allows the assessment to extend to primary data collection, which also produces subsequent advantages in secondary data analysis as indicated above. Using The Island for assessment allows students to demonstrate skills in all aspects of the research process across a single project: design, collection and analysis.

\subsection{Disconnection between strands}

The epidemiology and biostatistics strands can be connected better through simple changes to the course. For example, the teaching staff in both strands should adopt a consistent language, and ensure the connections between components of the course are explicitly communicated to students. The Island also facilitates a better connection between strands by allowing students to design, collect and analyse data as part of a single project. Tutorial exercises can be integrated as well: Epidemiological tutorial exercises can be used to generate data, which can be analysed in later biostatistical tutorials. 


\section{Summary}

In this paper, an epidemiology and statistics course has been evaluated in light of the university's desire to embed e-learning into the curriculum and increasing numbers of online students to the course. To assist in making the necessary changes, the course as a whole has been evaluated, and five areas of challenge identified. Some proposed solutions have been identified that impact the structure and teaching of the course as a whole. One suggestion of interest is the proposal to incorporate a virtual human population (The Island) as an avenue for introducing these solutions in a blended-learning context.

One limitation of the study is the small number of students who participated in the focus group. However, this constituted only one aspect of the data collection, and feedback from students was obtained by other means also.

In 2014, a revised PUB361 course was adopted and implemented, using The Island and adopting suggestions made from this study. Adoption of The Island will imply many changes to the course, including revisions of the tutorial material, using computer laboratories for both epidemiology and biostatistical tutorials, a revision of the assessment to use The Island, and the production of screencasts to assist students to use The Island. These innovations will be discussed and evaluated elsewhere.

\section{Acknowledgements}

The authors acknowledge financial support from the University of the Sunshine Coast's Open Learning and Teaching Grants Scheme A13443.

\section{References}

Australian Qualifications Framework [AQF]. (n.d.). Retreived March 20, 2015, from http://www.aqf.edu.au/.

Alammary, A., Sheard, J., \& Carbone, A. (2014). Blended learning in higher education: Three different design approaches. Australasian Journal of Educational Technology, 30(4), 440-454.

Arum, R., \& Roksa, J. (2011). Academicaly adrift: Limited learning on college campuses. Chicago: University of Chicago Press.

Bulmer, M. (2010). Technology for nurture in large classes. Fellowship report, Australian Learning and Teaching Council.

Bulmer, M. (2011). Collaborative development of a virtual environment to support learning in experimental design and statistical analysis. In: Proceedings 58th World Statistics Congress (ISI2011), Dublin, Ireland, 21-26 August 2011:1-7: 945-951.

Bulmer, M., \& Haladyn, K. (2011). Life on an Island: A simulated population to support projects in statistics. Technology Innovations in Statistics Education, 5(1), 1-20.

Carman, J. M. (2002). Blended learning design: Five key ingredients. Retrieved March 18, 2015, from www.agilantlearning.com\%2Fpdf\%2FBlended\%2520Learning\%2520Design.pdf 


\section{$\triangle$ Macrothink}

International Research in Education

ISSN 2327-5499

2016, Vol. 4, No. 1

Duchateau, L., Lievens, L., \& Darius, P. (2010). Setting up experiments in veterinary science: An example of virtual experimentation. In Proceedings of the 8th International Conference on Teaching Statistic (ICOTS8). Data and context in statistics education: Towards an evidence-based society, (ed C Reading), Ljubljana, Slovenia, 8 July 2010.

Everitt, B. (2006). The Cambridge Dictionary of Statistics. Cambridge: Cambridge University Press.

Forster, M., \& MacGillivray, H. (2010). Student discovery projects in data analysis. In: $8^{\text {th }}$ International Conference on Teaching Statistics . Data and context in statistics education: Towards an evidence-based society (ed C Reading), Ljubljana, Slovenia, 8 July 2010.

Graham, C. R. (2012). Blended learning systems: Definition, current trends, and future directions. In C. J. Bonk \& C. R. Graham (Eds.). Handbook of blended learning: Global perspectives, local designs (pp. 3-21). San Francisco, CA: John Wiley \& Sons.

Glaser, B. G., \& Strauss, A. L. (1967). The discovery of grounded theory: strategies for qualitative research. Chicago: Aldine.

Gurung R., Chick, N., \& Haynie, A. (2009). Exploring signature pedagogies: Approaches to teaching disciplinary habits of mind. Sterling, VA: Stylus Publishing, LLC.

Herrington J., Reeves T., \& Oliver, R. (2010). A Guide to Authentic e-Learning. New York: Routledge.

Kim, B., \& Reeves, T. (2007). Reframing research on learning with technology: In search of the meaning of cognitive tool. Instructional Science, 35(3), 207-256. http://dx.doi.org/10.1007/s11251-006-9005-2

Kuh, G. (2003). What we're learning about student engagement from NSSE. Change, 35(2), 24-32. http://dx.doi.org/10.1080/00091380309604090

Lee, M., \& McLoughlin, C. (2010). Web 2.0-based e-learning: Applying, social informatics for tertiary teaching. Hershey, PA: Information Science Reference.

Linden, M., Baglin, J., \& Bedford A. (2011). Teaching clinical trial design and management using an online virtual environment. In: Proceedings of the Australian Conference on Science and Mathematics Education 2011: Teaching for Diversity-Challenges and Strategies, (eds M Sharma, A Yeung, T Jenkins, E Johnson, G Rayner, and J West), Melbourne, 28-30 September 2011: 107-113.

Littlejohn, A., \& Pegler, C. (2007). Preparing for blended e-learning. Abingdon, Oxon: Taylor \& Francis.

Loke, S. K. (2015). How do virtual world experiences bring about learning? A critical review of theories. Australasian Journal of Educational Technology, 31(1), 112-122.

Meyer, J., \& Land, R. (2005). Threshold concepts and troublesome knowledge (2): Epistemological considerations and a conceptual framework for teaching and learning. Higher Education, 49, 373-388. http://doi 10.1007/s10734-004-6779-5. 
Print, M. (1993). Curriculum Design and Development. Allen \& Unwin.

Reeves, T., \& Reeves, P. (2012). Designing online and blended learning. In Hunt L, Chalmers D, (eds.) University Teaching in Focus: A learning-centred approach. Camberwell, Victoria: ACER Press, pp. 113-114.

Roberts, S. (2004). Online collaborative learning: Theory and practice. Hershey, PA: Information Science. http://dx.doi.org/10.4018/978-1-59140-174-2

Rumsey, D. J. (2002). Statistical literacy as a goal for introductory statistics courses. Journal of Statistics Education, 10(3).

Thomas, M. (2011). Digital education: Opportunities for social collaboration. New York: Palgrave Macmillan. http://dx.doi.org/10.1057/9780230118003

Wild, C. (2007). Virtual environments and the acceleration of experiential learning. International Statistical Review, 322-335. http://dx.doi.org/10.1111/j.1751-5823.2007.00033.x

University of the Sunshine Coast. (2012). Blended Learning at USC. Retrieved from http://www.usc.edu.au/university/learning-and-teaching/blended-learning-at-usc\#

\section{Copyright Disclaimer}

Copyright reserved by the authors.

This article is an open-access article distributed under the terms and conditions of the Creative Commons Attribution license (http://creativecommons.org/licenses/by/3.0/). 